https://doi.org/10.31470/2706-7904-2020-15-208-211

\title{
THE ROLE OF MOTIVATION IN THE DEVELOPMENT OF FOREIGN LANGUAGE COMPETENCE OF STUDENTS
}

\section{Роль мотивації в розвитку знань іноземної мови в студентів}

\author{
Kateryna Oleksandrenko \\ DSc. in Psychology, Associate Professor \\ Khmelnytskyi National University (Ukraine) \\ oleksandrenkok@gmail.com \\ https://orcid.org/0000-0001-9735-3715
}

\begin{abstract}
The thesis studies the phenomenon of motivation of students namely the study of its formation. As a task of the research the author has defined an attempt to assess and analyze the changes of formation of motivation of students after conducting experimental work. The author tries to trace the cognitive process and reveal differences in motivational orientations of students in control and experimental groups. The work is interdisciplinary in its nature and is written at the intersection of psychology and pedagogy. As the key evidence the author presents a positive change among the motives associated with future development of the personality which confirms the assumption about the need to focus on student's personality, his/her interests and development of personal values, i.e. correct orientation in a student-centered approach and self-actualization of individual students.
\end{abstract}

Key words: motivation, motive, competence, activity, communication.

\section{Introduction}

Communication has been connected with motives and needs of the personality. The problem of student's motivation in the development of foreign language competence is undeniable. But no one can make students experience something unless they realize and accept it. The problem of motivation in the process of learning may be described as transformation of the taught object into the subject of learning activity. Motivation is regarded as a call to action; dynamic psychophysiological process managing human's behavior, defining his direction, involvement, organization, sustainability. The investigation 
of the motives within the structure of the activity is the analysis of the internal activity management. The most valuable motives should become the driving force in the process of learning. Less valuable motives may be lowered.

\section{Methods and Techniques of the Research}

Within the frameworks of our investigation the following theoretical and empirical methods were employed: systematization, analysis, synthesis, comparison and generalization; analysis of empirical data, summarizing, content-analysis, expert assessment, standardized methodology of investigation of motives in learning activity elaborated by A. Rean (Rean \& Kolominsky, 2008), test - questionnaire «Motivation of Success and Fear of Failure» (Rean, 2004), methodology «The Study of Learning Motivation in a Higher Educational Establishment» by T. Ilyina (Ilyina, 2008).

\section{Results}

To investigate the motivational sphere formation 110 first- and second-year students were involved in the survey. The first stage of the research included the analysis of changes in motivational sphere of the students in control and experimental groups before and after the experiment. Significant differences in motivational orientations in both groups were not identified. At the beginning of the experimental work social motives (every person should know a foreign language $-4.8 / 3.2$, this subject is in the curriculum - 13.9/10.8, the English language is more interesting than other languages $-10.8 / 11.6$, it is impossible to read English signs and notes without appropriate knowledge of the English language - 3.1/2.9) and «antimotivation» (I would like to study French as it is more attractive - 1.3/1.5, I would like to study Chinese as it is more prospective $-2.6 / 2.3$ ) prevailed. The less important motives were communicative ones and those connected with the personality future development. After the experiment positive changes were identified: «antimotives» and social external motives were replaced by internal motives connected with the future professional activity. Thanks to the games and exercises which were used within the frameworks of the special course «The Role of the English Language in the Development of Students' Independence» the increase of communicative motives became obvious. Positive changes in the motives associated with the future development of personality confirm the assumption about the need to focus on student's personality. The proportion between «antimotives» and social motives aimed at external motivation in the experimental groups decreased. No changes were noticed in the control groups. We consider that social 
motivation in its wide meaning is less important for students than the results of their own activity, confidence in the success which contributed to the shift in learning activity.

Out of 16 motives in learning activity five the most significant were indicated. We distributed the questions into two groups depending on motivation type. By the end of the experiment positive changes were noticed in the experimental groups. The number of the first-year students with external motivation dropped by 24.5 per cent, in groups of the second-year students - by 18.9 per cent. In the control groups this figure grew up to 3.24 per cent for the first-year students and dropped by 5.67 per cent for the second-year students.

The internal motivation in the experimental groups of the first-year students grew by 12.5 per cent and for the second-year students - by 30.7 per cent. For the control groups this indicator among the first-year students increased by 4.62 per cent, and for the second-year students it decreased by 2.19 per cent.

Thus, the positive changes in the internal motivation indicators in the experimental groups allow us to assume that the elaborated model of foreign competence development by means of efficient organization of independent work is effective.

Methodology «The Study of Learning Motivation in a Higher Educational Establishment» by T. Ilyina contains three scales: «Knowledge Acquisition», «Profession Obtaining», «Diploma Obtaining». The results of our investigation testify to the fact that the desire to get a diploma prevailed among the students of both experimental and control groups. After the experiment the indicator on the scale «Knowledge Acquisition» increased by 3.7 scores for the first- and second-year students in the experimental groups. In the control group the indicator was only 1.7. According to the scale «Profession Obtaining» the indicator increased by 4 scores and 2.2 scores in the corresponding groups. On the scale «Diploma Obtaining» the indicators decreased by 3.2 and 0.6 scores relatively. Prevailing of the motives on the first two scales after the experiment testifies to the adequate choice of the profession by the students and their satisfaction.

Test - questionnaire «Motivation of Success and Fear of Failure» by A. Rean we used to diagnose the students' motivational pole. The data obtained show positive changes in motivation of success for the students of the experimental groups. Its indicators increased by 44.2 per cent for the first-and second-year students. For the control group this indicator increased by 18.5 per cent. Figures for the fear of failure after the experiment decreased by 45.51 per cent for the experimental group, for the control group it was 11.39 per cent.

Diagnostics of motivation of professional activity was based on the concept of internal and external motivation. On the basis of the obtained results motivational complex of personality was determined. The type ENM $>$ EPM $>$ IM as the worst motivational complex got the most scores before the experimental work (where ENP is external negative motivation, EPM - external positive motivation, IM - internal motivation). After the 
experiment the given indicator dropped from 86.05 to 22.5 per cent for the first-year students and from 99.9 to 52.8 per cent for the second-year students. Indicators for the type $\mathrm{IM}>\mathrm{EPM}>\mathrm{ENM}$ and IM=EPM $>\mathrm{ENM}$ (the best complex) increased after the experimental work in the experimental group by 45.5 per cent for the first-year students and by 48.7 per cent for the second-year students. For the control group the figure was 15.7 and 29.6 per cents respectively. As a result we can say that the students of the experimental group by the end of the experiment were more orientated on inner motives rather than the students of the control group.

We suggested the students the tasks for independent work contributing to the formation and development of learning internal motives: to compile the tasks to the text (exercises, quizzes, crosswords, thematic illustrative dictionary, riddles); to invent the contest, the game; to translate the poem into the Ukrainian language; to invent the tourist route.

\section{Conclusions}

To summarize it we can assert that the development of motivation for the learning of foreign language by means of different tasks for independent work promotes the formation and development of internal sustainable motives of learning which positively influence the activity on the whole.

\section{References}

Rean, A., \& Kolominsky, Ya. (2008). Sotsialnaya pedagogicheskaya psikhologiya. St. Petersburg: Prime-Evroznak. [Social pedagogical psychology] [in Russian]. 